\title{
Role of IL-33 expression in oncogenesis and development of human hepatocellular carcinoma
}

\author{
YAN YANG $^{1}$, JUN-BIN WANG $^{1}$, YU-MEI LI $^{1}$, YU ZHAO $^{1}$, RUI WANG $^{1}$, \\ QIONG WU ${ }^{1}$, RONG-SHENG ZHENG ${ }^{1}$ and YU-RONG OU ${ }^{2}$
}

Departments of ${ }^{1}$ Medical Oncology and ${ }^{2}$ Pathology, The First Affiliated Hospital of Bengbu Medical College, Bengbu, Anhui 233004, P.R. China

Received March 28, 2015; Accepted April 22, 2016

DOI: $10.3892 / \mathrm{ol} .2016 .4622$

\begin{abstract}
Interleukin-33 (IL-33), a newly-discovered cytokine belonging to the IL-1 family, serves an important role in inflammation. However, it is not clear whether IL-33 is of clinical significance in hepatocarcinogenesis. The present study was designed to investigate the role of IL-33 during oncogenesis and development of hepatocellular carcinoma (HCC). IL-33 protein expression was detected in $76 \mathrm{HCC}$ (including 36 para-carcinoma), 33 cirrhosis, 30 hepatitis, and 20 normal liver tissues using immunohistochemistry. IL-33 mRNA expression in carcinoma and para-carcinoma tissues was evaluated by reverse transcription-polymerase chain reaction (RT-PCR). The possible correlation between IL-33 and clinicopathological parameters of HCC was also analyzed. Significant differences in IL-33 expression were not observed among normal, hepatic, and cirrhotic tissues $(\mathrm{P}>0.05)$, whereas the level of protein positive rate was markedly reduced in $\mathrm{HCC}$ tissues $(\mathrm{P}<0.01)$. Positive staining of IL-33 in non-cancerous liver (NCL) tissues (i.e. normal, hepatitis, and liver cirrhosis) was located predominantly in the nucleus and occasionally in the cytoplasm of hepatocytes; however, the expression in HCC tissues was mostly restricted to the cytoplasm. A significant alteration in protein localization was observed in HCC tissues as compared with NCL tissues $(\mathrm{P}<0.01)$. In comparison with HCC tissues, cytoplasmic staining of IL-33 was increased in para-carcinoma tissues. RT-PCR assay further confirmed relatively high mRNA expression levels of IL-33 in para-carcinoma tissues. IL-33 expression was significantly negatively associated with tumor histological grade $(r=-0.279, \mathrm{P}=0.015)$, but not with year, gender, tumor size, clinical stage, HCC with hepatitis and cirrhosis background, lymph node metastasis or intrahepatic vascular embolism $(\mathrm{P}>0.05)$. Therefore, the
\end{abstract}

Correspondence to: Professor Yu-Rong Ou, Department of Pathology, The First Affiliated Hospital of Bengbu Medical College, 287 Changhuai Road, Bengbu, Anhui 233004, P.R. China

E-mail: snowyc1220@163.com

Key words: interleukin-33, hepatocellular carcinoma, inflammation, hepatocarcinogenesis, immunohistochemistry aberrant expression of IL-33 is associated with oncogenesis and progression of $\mathrm{HCC}$ and the cytoplasmic accumulation of the protein may serve a role in hepatocarcinogenesis.

\section{Introduction}

A large number of studies have demonstrated that inflammatory process, mediated by the complex cytokine network, is associated with a variety of tumors $(1,2)$. Hepatocellular carcinoma (HCC), a frequently occurring malignancy with a high rate of mortality, is considered to be associated with the development of chronic inflammation from hepatitis B and C infection $(3,4)$; however, the crucial molecular pathways that permit communication between abnormally HCC and various inflammatory cells are poorly understood. Interleukin-33 (IL-33), a newly-discovered cytokine, belongs to the IL-1 family (5). By binding to the homolog of sulfotransferase (ST2) receptor, IL-33 activates nuclear factor $\kappa \mathrm{B}(\mathrm{NF} \kappa \mathrm{B})$ and mitogen-activated protein kinase (MAPK) signaling pathways, thereby regulating variety of inflammatory and immune reactions $(5,6)$. In addition, IL-33 also acts as a chromatin-associated factor in the nucleus, thereby exhibiting transcriptional repressor properties for the regulation of gene transcription (7). The dual effects of IL-33 has attracted attention in the study of tumor pathogenesis. In vitro experiments have confirmed that carcinoma-associated fibroblasts (CAFs), a major type of tumor-surrounding stromal cell, promoted cancer invasiveness via paracrine and autocrine effects on microenvironmental IL-33 signaling (8). Experiments on animal models have demonstrated that the activation of IL-33/ST2 pathway promoted breast cancer growth and metastases by facilitating intratumoral accumulation of immunosuppressive and innate lymphoid cells (9). Serum IL-33 levels have been considered as a poor prognosis biomarker for a number of types of tumor, including gastric cancer (10), nonsmall-cell lung cancer (11), and breast cancer (12). In contrast to these findings, other studies have reported IL-33 as a potent inducer of anticarcinogenic immunity, which results in enhanced activation of cytotoxic CD8+ cells (13). Thus, the association between IL-33 expression and tumor development appears controversial. In terms of liver disease, studies have demonstrated that hepatocytes strongly expressed IL-33 in concanavalin A-induced hepatitis model (14). Together with upregulation of other 
proinflammatory factors, the increase of serum IL-33 serves a role in the development of chronic viral hepatitis (15), hepatic fibrosis (16) and HCC (17). These findings indicated that IL-33 may be important in promoting the oncogenesis and development of HCC. However, other previous studies questioned the effect of IL-33 in HCC patients (18) or even rendered the hepatoprotective role of IL-33 in liver disease (19). The present study investigated the expression and localization of IL-33 in HCC and non-cancerous liver (NCL) tissues during different conditions, including normal liver, chronic hepatitis, and liver cirrhosis by immunohistochemistry. In addition, the present study also analyzed the correlation between IL-33 and clinicopathological parameters of HCC. The objective of the present study was to investigate the role of IL-33 in the oncogenesis and progression of $\mathrm{HCC}$, which may provide novel histological data and theoretical basis for HCC inflammatory pathogenesis.

\section{Materials and methods}

Samples. A total of 76 cases of HCC following surgical resection were collected from the First Affiliated Hospital of Bengbu Medical College (Bengbu, China) between January 2008 and December 2013. The patients received no treatment preoperatively, and completed clinical data was obtained. The pathological grading was defined by Edmondson and Steiner classification (20): Grade I-II tumors accounted for $63 \%$ (48 samples), and grade III-IV tumors accounted for $37 \%$ (28 samples) of the patient samples. The HCC study population included 61 males and 15 females. The age of participants ranged between 22-76 years, with a median age of 50 years. For the 36 para-carcinoma controls, tissues adjacent to carcinoma, which were diagnosed as normal by the pathological methods, were taken from tissue $\geq 5 \mathrm{~cm}$ away from the tumor in HCC patients.

During the same period, 33 cases (23 males and 10 females) of cirrhosis were also collected. The age of participants ranged between 20-77 years, with a median age of 47 years. A total of 30 cases ( 21 males and 9 females) of hepatitis were also collected. The age ranged from 18-49 years, with a median age of 33.5 years. Chronic hepatitis and liver cirrhosis was pathologically confirmed by needle biopsy. In addition, 20 cases (11 males and 9 females) of normal liver tissue (specimens following traumatic liver resection, or from healthy subjects following accidental death) were used as control. The age of participants ranged between $21-73$ years, with a median age of 54.5 years. Approval was obtained from the medical ethics committee of Bengbu Medical College (Bengbu, China), and written informed consent was obtained from the patient or their immediate family members.

Immunohistochemistry. All specimens were embedded in paraffin and were cut into $4-\mu \mathrm{m}$ sections by a microtome. Immunohistochemical staining was performed according to previously described standard protocols $(21,22)$. More specifically, tissue sections were baked at $62^{\circ} \mathrm{C}$ for $30 \mathrm{~min}$, deparaffinized in xylene (Beijing Zhongshan Golden Bridge Biotechnology Co., Ltd., Beijing, China) and rehydrated in graded ethanol prior to pretreatment with 3\% hydrogen peroxide/methanol solution (Sinopharm Chemical Reagent Co., Ltd., Beijing, China) for 15 min to block endogenous peroxidase activity. The sections were then washed 3 times in $\mathrm{PBS}$, and heated in a microwave oven in the presence of $0.01 \mathrm{M}$ citric acid buffer pH 6.0 (Beijing Zhongshan Golden Bridge Biotechnology Co., Ltd.) for $15 \mathrm{~min}$, and gradually cooled down to room temperature. Sections were subsequently incubated with goat anti-human IL-33 polyclonal antibody (1:200 dilution; catalog no. AF3625; R\&D Systems, Abingdon, UK) at $4^{\circ} \mathrm{C}$ overnight. The sections were then washed 3 times with PBS, incubated for $20 \mathrm{~min}$ at room temperature in a humidified chamber with reagent 1 (polymer auxiliary agent; Beijing Zhongshan Golden Bridge Biotechnology Co., Ltd.), washed again with PBS, and incubated for $30 \mathrm{~min}$ at $37^{\circ} \mathrm{C}$ with horseradish peroxidase-conjugated anti-goat IgG (catalog no. PV-9003; ready to use; Beijing Zhongshan Golden Bridge Biotechnology Co., Ltd.). The slides were stained using a DAB staining kit (Fuzhou Maixin Biotech Co., Ltd., Fuzhou, China), counterstained with hematoxylin (Beyotime Institute of Biotechnology, Shanghai, China) at $37^{\circ} \mathrm{C}$ for $3-5 \mathrm{~min}$, and mounted. The negative control slides were processed by omitting the primary antibody, but including all other steps of the procedure. Protein positive staining and cellular localization were observed and images were captured by light microscope (Olympus BH-12, Tokyo, Japan).

Evaluation of staining. Microscopic analysis of IL-33 was assessed independently by two observers in a blinded manner. There was no discrepancy between the two investigators. The cells with nuclear and/or cytoplasmic marking were considered positive, and subjective estimation was judged according to the criteria described by Goncalves et al (23). Nuclear IL-33 expression was scored by determining the percentage of nuclei with IL-33 immunoreactivity, and was grouped as follows: Low expression ( $<50 \%$ positive cells) and high expression ( $\geq 50 \%$ of the cells showing nuclear immunoreactivity). For cytoplasmic IL-33 staining, the positive cells were also grouped as low expression (weak pale brown staining) and high expression (strong dense brown staining) cells. The result was defined as negative if neither the nucleus or cytoplasm was stained. A total of 5 visual fields were chosen randomly by high-power lens (x40 magnification) with 3 replicates, and the final evaluation was derived from the average of staining results either in the nucleus or cytoplasm.

Reverse transcription-polymerase chain reaction (RT-PCR). RNA isolation and RT-PCR procedure was conducted as previously described (24). Briefly, total RNA was isolated from flash-frozen liver tissues using the TriZOL reagent (Invitrogen; Thermofisher Scientific, Inc., Waltham, MA, USA) and then converted to complementary DNA (cDNA) with avian myeloblastosis virus reverse transcriptase (Promega Corporation, Madison, WI, USA). A total of $2 \mu \mathrm{l}$ of cDNA was amplified in a $20 \mu \mathrm{l}$ standard PCR reaction. The PCR was initiated at $94^{\circ} \mathrm{C}$ for $3 \mathrm{~min}$ followed by 35 cycles consisting of $45 \mathrm{sec}$ at $94^{\circ} \mathrm{C}, 45 \mathrm{sec}$ at $55^{\circ} \mathrm{C}$, and $45 \mathrm{sec}$ at $72^{\circ} \mathrm{C}$, with the final cycle extended to $10 \mathrm{~min}$ at $72^{\circ} \mathrm{C}$, followed by termination at $4^{\circ} \mathrm{C}$. The following primers were used: Human IL-33, F 5'-TCAGGT GACGGTGTTGATGG-3' and R 5'-ACAAAGAAGGCCTGG TCTGG-3', product size 140 bps; Human $\beta$-actin, F 5'-CTA AGTCATAGTCCGCCTAGAAGCA-3' and R 5'-TGGCAC CCAGCACAATGAA-3', product size 186 bps. The detection 


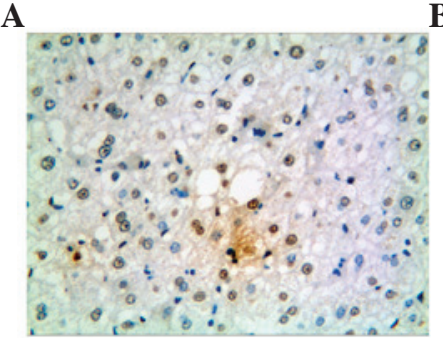

D

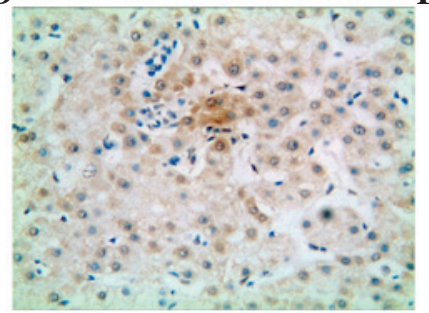

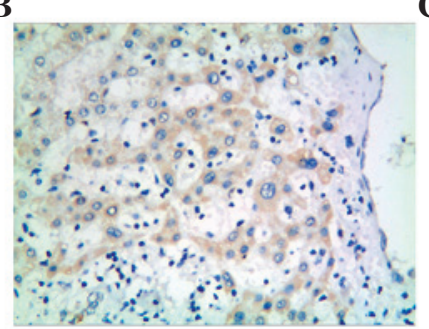

E

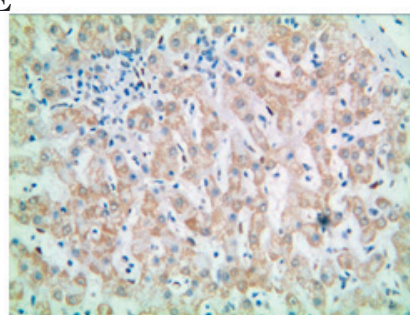

C

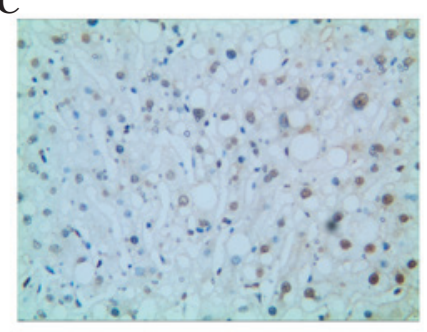

$\mathbf{F}$

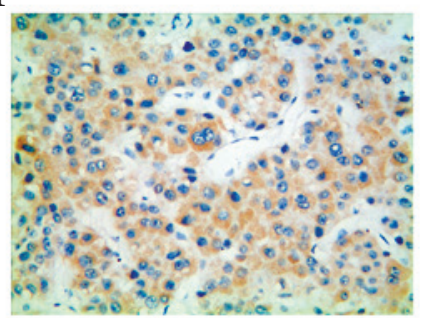

Figure 1. Immunohistochemical analyses of IL-33 expression in sections of different liver tissues. Normal liver cells showing both extensive (A) nuclear and (B) cytoplasmic staining for IL-33. (C) Nuclear positive staining for IL-33 in chronic hepatitis tissues. Expression of IL-33 in (D) nucleus and (E) cytoplasm of cirrhosis liver tissues. (F) Diffused cytoplasmic staining of IL-33 in hepatocellular carcinoma tissues. Representative immunohistochemical examples of staining are shown (original magnification, x400). IL-33, interleukin-33.

Table I. Expression of IL-33 in NCL and HCC tissues.

\begin{tabular}{llrrr}
\hline & & \multicolumn{2}{c}{ IL-33 } & \\
\cline { 3 - 4 } Group & $n$ & - & + & Significance $\left(\chi^{2}\right.$ test) \\
\hline HCC & 76 & $59(77.63 \%)$ & $17(22.37 \%)$ & P $=0.007$ \\
NCL & 83 & $47(56.63 \%)$ & $36(43.37 \%)$ & NS \\
Normal liver & 20 & $12(60.00 \%)$ & $8(40.00 \%)$ & \\
Hepatitis & 30 & $14(46.67 \%)$ & $16(53.33 \%)^{\mathrm{a}}$ & $12(36.36 \%)$ \\
Cirrhosis & 33 & $21(63.64 \%)$ & $12 \%)$ & \\
\hline
\end{tabular}

${ }^{a} \mathrm{P}<0.01$ vs. HCC group; $\chi^{2}$ test was used to analyze the protein positive rate among the multiple groups, and the significant level $\alpha$ was corrected. IL-33, interleukin-33; NCL, non-cancerous liver; HCC, hepatocellular carcinoma; NS, non-significant.

of $\beta$-actin transcripts provided an internal control for PCR, standardizing the quantity of input cDNA. PCR products were analyzed on an ethidium bromide-stained $2 \%$ agarose gel.

Statistical analysis. All statistical analyses were performed using Statistical Package for the Social Sciences (SPSS) version 17.0 statistical software (Chicago, IL, USA). The expression of IL-33 in distinct tissue types and the association between the marker and clinicopathological parameters were evaluated by $\chi^{2}$ test and Fisher's exact test, wherever appropriate. Comparison of numerical data was achieved with the unpaired Student's $t$-test. $\mathrm{P}<0.05$ indicates a statistically significant difference.

\section{Results}

IL-33 expression in HCC and NCL tissues. As presented in Fig. 1, IL-33 is visually located in the nucleus and cytoplasm of hepatocytes. The positive rates in normal liver tissues, hepatitis tissues, and cirrhosis tissues were $40.00 \%(8 / 20)$, $53.33 \%$ (16/30), and 36.36\% (12/33), respectively. Statistically significant differences were not observed between these three groups $\left(\chi^{2}=1.965, \mathrm{P}>0.05\right.$, Table I). However, when compared to the total NCL tissues, the rate of IL-33 protein expression in HCC tissues was markedly reduced to $22.37 \%\left(17 / 76 ; \chi^{2}=7.877\right.$, $\mathrm{P}=0.007$, Table I).

IL-33 localization in HCC and NCL tissues. Nucleic and cytoplasmic staining of IL-33 was observed in the normal liver tissue (Fig. 1A and B); whereas in hepatitic liver tissue, IL-33 expression was only observed in the nucleus, but not in the cell membrane or cytoplasm (Fig. 1C). However in chronic cirrhosis liver, nucleus staining of IL-33 was observed in only 1 case, both cytoplasmic and nuclear staining in 3 cases (Fig. 1D), whereas 29 cases demonstrated rich cytoplasmic expression of IL-33 (Fig. 1E). In HCC tissues, all the IL-33-positive HCCs showed cytoplasmic staining (Fig. 1F), with only 3 cases of concurrent nuclear staining. Statistical analysis indicated that with the progression of liver disease from normal to hepatitis, cirrhotic, and HCC, the localization of IL-33 gradually changes from the nucleus to cytoplasm, with the difference in expression of cytoplasmic IL-33 between NCL and HCC 
Table II. Intracytoplasmic positive staining of IL-33 in NCL and HCC tissues.

\begin{tabular}{|c|c|c|c|c|}
\hline \multirow[b]{2}{*}{ Group } & \multirow[b]{2}{*}{ All positive cases $(n)$} & \multicolumn{2}{|c|}{ IL-33 localized in cytoplasm } & \multirow[b]{2}{*}{ Significance ( $\chi^{2}$ test $)$} \\
\hline & & Cases $(n)$ & Rate $(\%)$ & \\
\hline $\mathrm{HCC}$ & 17 & 17 & $100.00^{\mathrm{a}, \mathrm{b}}$ & \multirow{5}{*}{$\mathrm{P}=0.000$} \\
\hline NCL & 36 & 13 & 36.11 & \\
\hline Normal liver & 8 & 4 & 50.00 & \\
\hline Hepatitis & 16 & 0 & $0.00^{\mathrm{a}}$ & \\
\hline Cirrhosis & 12 & 9 & $75.00^{\mathrm{b}}$ & \\
\hline
\end{tabular}

${ }^{a} \mathrm{P}<0.01$ vs. normal group; ${ }^{b} \mathrm{P}<0.01 \mathrm{vs}$. hepatitis group; $\chi^{2}$ test was used to analyze the protein positive rate among the multiple groups, and the significant level $\alpha$ was corrected. IL-33, interleukin-33; NCL, non-cancerous liver; HCC, hepatocellular carcinoma.

Table III. IL-33 expression level in NCL and HCC tissues.

\begin{tabular}{|c|c|c|c|c|c|c|c|c|}
\hline \multirow[b]{2}{*}{ Group } & \multicolumn{4}{|c|}{ Nuclear IL-33 expression } & \multicolumn{4}{|c|}{ Cytoplasmic IL-33 expression } \\
\hline & $n$ & High & Low & P-value & $n$ & High & Low & P-value \\
\hline $\mathrm{HCC}$ & 3 & 0 & 3 & 1.000 & 17 & 14 & 3 & $0.010^{\mathrm{a}}$ \\
\hline NCL & 24 & 5 & 19 & & 15 & 5 & 10 & \\
\hline Normal liver & 4 & 0 & 4 & $0.018^{\mathrm{a}}$ & 4 & 0 & 4 & \\
\hline Hepatitis & 16 & 2 & 14 & & 0 & 0 & 0 & 0.231 \\
\hline Cirrhosis & 4 & 3 & 1 & & 11 & 5 & 6 & \\
\hline
\end{tabular}

${ }^{a} \mathrm{P}<0.05 ; \chi^{2}$ test. IL-33, interleukin-33; NCL, non-cancerous liver; HCC, hepatocellular carcinoma.

A

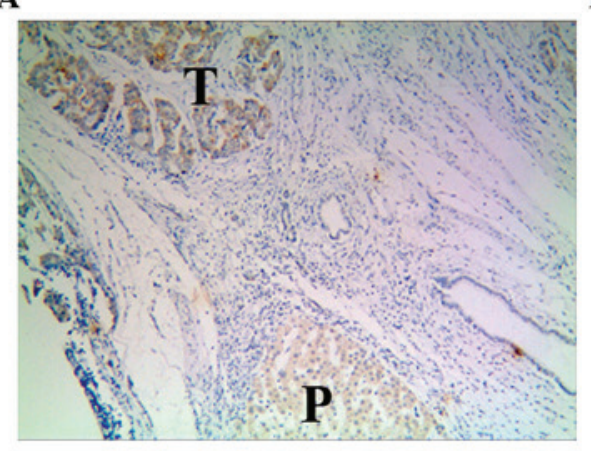

C

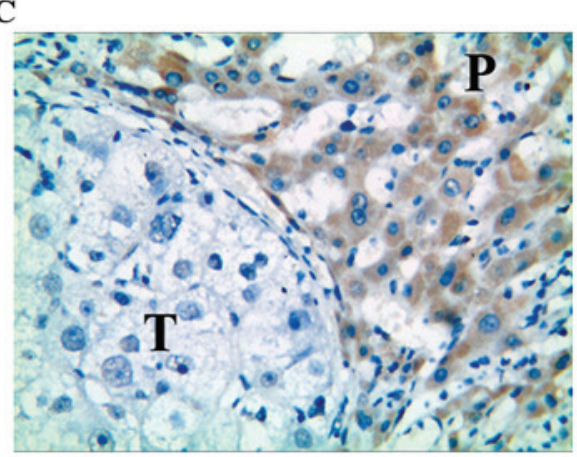

B

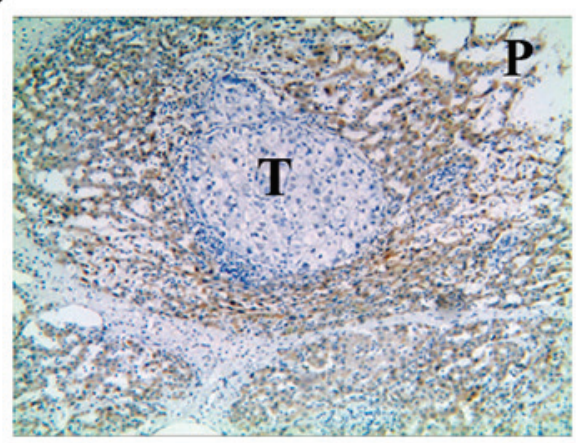

D

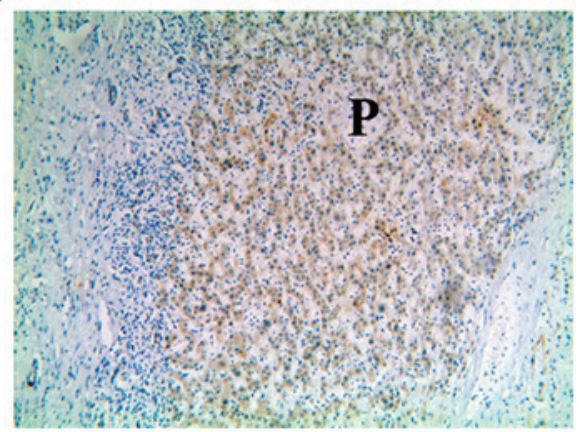

Figure 2. Expression of IL-33 in hepatic carcinoma and para-carcinoma tissues. (A) IL-33-positive cytoplasmic staining in HCC tissue and para-carcinoma tissue. (B) Negative staining of IL-33 was observed in cancerous cells, while diffused cytoplasmic staining was observed in para-cancerous liver cells. (C) Enlarged view of (B). (D) IL-33-positive cytoplasmic staining in para-carcinoma tissue from another patient. Representative immunohistochemical examples of staining were shown (A, B and D, original magnification x100; C, original magnification x400). IL-33, interleukin-33; T, tumor; P, para-tumor; HCC, hepatocellular carcinoma. 
Table IV. Expression of IL-33 in carcinoma and para-carcinoma liver tissues.

IL-33

\begin{tabular}{|c|c|c|c|c|c|}
\hline \multirow[b]{2}{*}{ Group } & \multirow[b]{2}{*}{$n$} & & \multirow[b]{2}{*}{$\chi^{2}$ value } & \multirow[b]{2}{*}{$\mathrm{P}$-value } \\
\hline & & - & + & & \\
\hline Carcinoma & 76 & $59(77.63 \%)$ & $17(22.37 \%)$ & \multirow{2}{*}{14.095} & \multirow{2}{*}{$0.000^{\mathrm{a}}$} \\
\hline Para-carcinoma & 36 & $15(41.67 \%)$ & $21(58.33 \%)$ & & \\
\hline
\end{tabular}

${ }^{\mathrm{a}} \mathrm{P}<0.01 ; \chi^{2}$ test. IL-33, interleukin-33.

being statistically significant $\left(\chi^{2}=19.188, \mathrm{P}<0.0001\right.$, Table II $)$. In NCL, the cytoplasmic IL-33 was expressed at a low level, whereas in $\mathrm{HCC}$, the expression was comparatively higher $\left(\chi^{2}=7.938, P=0.010\right.$, Table III $)$.

IL-33 expression and localization in carcinoma and para-carcinoma tissues. When comparing the expression of IL-33 in carcinoma and para-carcinoma tissues, it was observed that when cancer cells were stained positive for IL-33 protein, positive staining was also detected in para-carcinoma tissues (Fig. 2A). IL-33 in para-carcinoma tissues was also noted in a proportion of the specimens for which the carcinoma cells exhibited negative IL-33 expression (Fig. 2B and C). The positive rate of IL-33 expression in para-carcinoma tissues was as high as $58.33 \%\left(21 / 36 ; \chi^{2}=14.095, \mathrm{P}<0.0001\right.$, Table IV). The staining of IL-33 in the two types of liver tissues was mostly observed in the cytoplasm (Fig. 2). To verify the results of immunohistochemistry, IL-33 mRNA expression was further assessed by RT-PCR. The results indicated that IL-33 mRNA levels were significantly higher in adjacent para-carcinoma tissues compared with primary liver carcinoma tissues $(\mathrm{P}<0.01$, Fig. 3).

Association between IL-33 expression and HCC clinical pathological characteristics. The expression of IL-33 in different subgroups was compared and is summarized in Table V. From the results, it was inferred that IL-33 status was not associated with patient age, gender, tumor size, TNM stage, cirrhosis or hepatitis background, lymph node metastasis, or intrahepatic vascular embolism $(\mathrm{P}>0.05)$; but it was associated with histological grade $\left(\chi^{2}=5.918, P=0.021\right)$. In addition, it was observed that histological grade and IL-33 positive expression were negatively correlated $(r=-0.279, \mathrm{P}=0.015)$. Notably, among all the IL-33-positive HCCs, the only 3 cases that exhibited both cytoplasmic and nuclear staining, belonged to I-II histological grade.

\section{Discussion}

Chronic inflammation serves a key role in the development of liver tumor, particularly for HCC $(3,4)$. HCC develops as a result of various chronic liver injuries, such as viral hepatitis and alcoholic hepatitis, which is vital mechanism of liver injury repair (25). However, during the repair of liver injury by inflammation, additional reactions develop simultaneously, including hepatic fibrosis and cirrhosis. These reactions contribute to the growth and metastasis of tumor, where

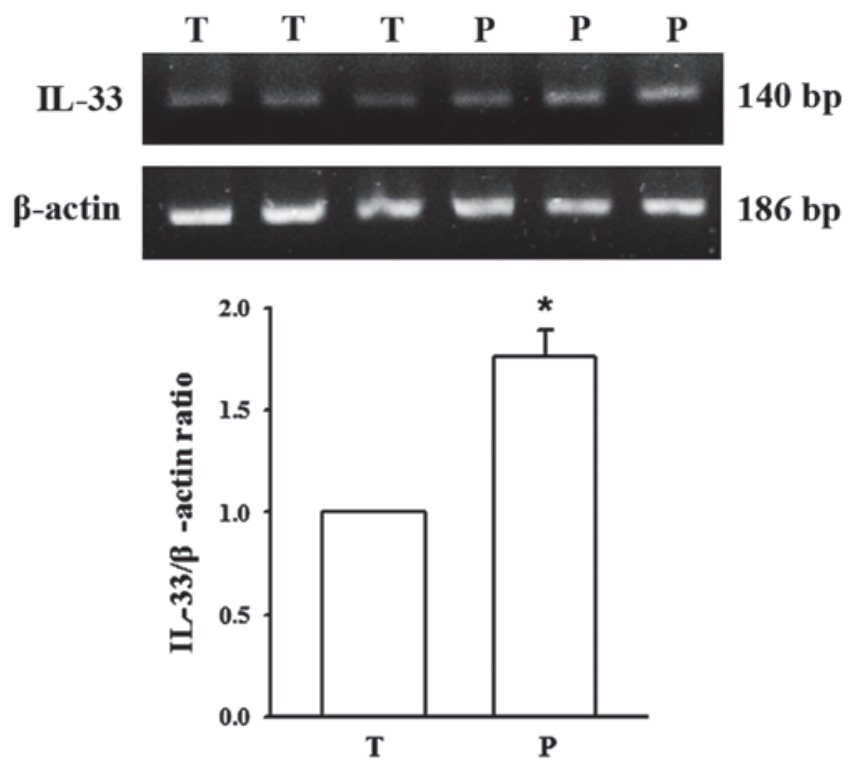

Figure 3. Reverse transcription-polymerase chain reaction analysis of IL-33 mRNA expression. The level of IL-33 mRNA expression (IL-33/ $\beta$-actin ratio) was significantly higher in para-carcinoma tissues than that of primary liver carcinoma. Data represent the mean \pm standard error of the mean vs. tumor group, ${ }^{*} \mathrm{P}<0.01$. IL-33, interleukin-33; T,tumor; $\mathrm{P}$, para-tumor.

inflammatory cytokine-mediated abnormal signal transduction serves a major role. IL-33, which was first separated from endothelial cells by Baekkevold, was originally called 'nuclear factor derived of endothelial cell' (26). It was further discovered as a novel cytokine belonging to the IL-1 family, when comparing the homology of the IL-33 with that of IL-1 (5). Therefore, IL-33 is a dual-function protein that acts as an intracellular nuclear factor and a secreted cytokine. IL-33 has been demonstrated as an abundant chromatin-associated factor in the nucleus of endothelial cells, where it exhibits transcriptional repressor properties (7). Notably, IL-33 has also been identified as the natural ligand for ST2 receptor $(5,27)$, thereby activating $\mathrm{NF}-\kappa \mathrm{B}$ and other downstream molecules, which also explains why IL-33 and IL-1 share similar receptor signaling pathways (28). Currently, it is proposed that IL-33 is released upon cellular injury as a 30-kDa molecule (full-length IL-33) and is processed into less active, but more mature forms of 20-22 kDa units by caspase cleavage $(29,30)$. Research has indicated that the full-length IL-33 precursor, located in the nucleus, functions as a nuclear factor with transcriptional regulatory activity, while the mature IL-33 in cytoplasm may be involved in inflammatory reaction (31). In cells which 
Table V. Association between IL-33 expression and clinicopathological parameters.

\begin{tabular}{|c|c|c|c|c|c|}
\hline \multirow[b]{2}{*}{ Variable } & \multirow[b]{2}{*}{$n$} & \multicolumn{2}{|c|}{ IL-33 } & \multirow[b]{2}{*}{$\chi^{2}$ value } & \multirow[b]{2}{*}{ P-value } \\
\hline & & - & + & & \\
\hline Age (years) & & & & 0.079 & 0.746 \\
\hline$<60$ & 60 & 47 & 13 & & \\
\hline$\geq 60$ & 16 & 12 & 4 & & \\
\hline Gender & & & & 0.962 & 0.498 \\
\hline Male & 61 & 46 & 15 & & \\
\hline Female & 15 & 13 & 2 & & \\
\hline Tumor size (cm) & & & & 0.045 & 1.000 \\
\hline$\leq 5$ & 43 & 33 & 10 & & \\
\hline$>5$ & 33 & 26 & 7 & & \\
\hline Edmondson type & & & & 5.918 & $0.021^{\mathrm{a}}$ \\
\hline I-II & 48 & 33 & 15 & & \\
\hline III-IV & 28 & 26 & 2 & & \\
\hline TNM stage & & & & 1.461 & 0.365 \\
\hline I-II & 54 & 40 & 14 & & \\
\hline III-IV & 22 & 19 & 3 & & \\
\hline Cirrhosis or hepatitis background & & & & 1.256 & 0.500 \\
\hline Present & 60 & 45 & 15 & & \\
\hline Absent & 16 & 14 & 2 & & \\
\hline Lymph node metastasis & & & & 0.700 & 0.723 \\
\hline Negative & 62 & 47 & 15 & & \\
\hline Positive & 14 & 12 & 2 & & \\
\hline Intrahepatic vascular embolism & & & & 0.089 & 1.000 \\
\hline Present & 20 & 16 & 4 & & \\
\hline Absent & 56 & 43 & 13 & & \\
\hline
\end{tabular}

${ }^{\mathrm{a}} \mathrm{P}<0.05 ; \chi^{2}$ test.

express ST2, IL-33 interacts with ST2 to activate NF- $\mathrm{BB}$ and MAPK signaling pathway, thereby leading to the induction of cytokines and subsequent modulation of T helper type 2 (Th2) cells' regulatory functions (32). Considering the dual function of IL-33, IL-33 may also serve significant roles in carcinogenesis and tumor progression.

The present study demonstrated that IL-33 is moderately expressed in normal liver tissues and is located in both liver nucleus and cytoplasm. The results indicated that IL-33 may have dual functions both as nuclear factor and inflammatory mediators in normal hepatocytes at physiological state. In hepatitis patients, the expression rate and level of IL-33 were similar to that of normal liver, yet all positive IL-33 expression was solely located in nucleus. This indicated the active transcription inhibition properties of IL-33 may serve a role during early inflammatory response. This property may inhibit the expression of a number of associated cytokines and proteins, and therefore avoids excessive inflammatory reaction. The protective role of IL-33 for liver injury was demonstrated previously. Sakai et al (19) reported that in the hepatic response to ischemia/reperfusion, IL-33 appeared to have direct protective effects on hepatocytes that limits liver injury and reduces the stimulus for inflammation. However, the continuous inflammatory reaction keeps the repair mechanism of the liver active and leads to the aggravation of hepatic fibrosis and eventually results in the development of cirrhosis. The present study confirmed this hypothesis; IL-33 tended to be located in cytoplasm in cirrhosis tissues, which is consistent with previous report (16). Therefore, the localization of IL-33 in cells will change with the associated biological function of IL-33 during different stimuli. One hypothesis is that when the balance of the dual functions of IL-33 is altered, the activated IL-33 is released from the nucleus and is synthesized largely in the cytoplasm. The precursor IL-33 is cleaved into the mature protein by caspase- 1 , which acts together with the transmembrane receptor ST2 to regulate the inflammatory reaction. When liver injury progresses to carcinoma, the positive expression of IL-33 in HCC is markedly decreased when compared to NCL, thereby indicating the diminish effect of IL-33 as protective factor in the development and progression of HCC. However, this hypothesis needs further study to prove. Additionally, it was observed in the present study that the small amount of positive IL-33 in HCC was mostly recognized as cytoplasmic accumulation. This finding was in accordance with the localization of IL-33 in HCC tissue as described by Zhang et al (17), thereby rendering the role 
of IL-33 as an inflammatory mediator in HCC cells. While considering the expression of IL-33 in para-carcinoma tissues, the rate of protein expression was highly positive and located predominantly in the cytoplasm of liver cells. Subsequent RT-PCR analysis further confirmed an increase in IL-33 mRNA expression in para-carcinoma tissues compared to that in primary liver carcinoma tissues. The present authors speculate that in response to hepatocarcinogenic factors, IL-33 may be recruited in the tumor microenvironment, cytoplasmic IL-33 accumulation activates its downstream signalling pathways and induces subsequent inflammatory regulatory biological functions. Thus, IL-33 in para-tumor hepatocytes may be an important endogenous chemotactic factor, and its expression level may determine the biological behaviors and outcomes in pathological liver.

On further analyzing the correlation between the expression of IL-33 and HCC clinical pathological characteristics, it was observed that the level of IL-33 expression was not associated with patient age, gender, tumor size, TNM stage, cirrhosis or hepatitis background, lymph node metastasis or intrahepatic vascular embolism, but was associated with the histological grade. The expression of IL-33 in the highly differentiated group (I-II) was higher than the low differentiation group (III-IV). To some extent, the differentiation level reflects the malignant grade of the cancer cells. The low-differentiated cells have higher malignancy and exhibit more chances of recurrence and metastasis. Thus the association between IL-33 and histological grade further highlights the protective effect of IL-33 in liver under pathophysiological conditions (19).

In conclusion, during the progression of liver disease from normal tissue to hepatitis, cirrhotic, and HCC, the expression and localization of IL-33 are altered, which leads to a reduction in its protective effect. Although further studies are warranted to explore the mechanisms of downregulation and cytoplasmic retention of IL-33, the elucidation of the important dual role of IL-33 and its mediated signaling pathways may result in novel directions and strategies for the diagnosis and treatment of HCC.

\section{Acknowledgements}

The present study was supported by the National Natural Science Foundation of China (grant no. 81402514), a grant from the Natural Science Foundation of Anhui Province, China (grant no. 1408085QH166), and an internal grant from Bengbu Medical College (grant no. Bykf13A12).

\section{References}

1. Marx J: Cancer research. Inflammation and cancer: The link grows stronger. Science 306: 966-968, 2004.

2. Hofseth LJ and Ying L: Identifying and defusing weapons of mass inflammation in carcinogenesis. Biochim Biophys Acta 1765: 74-84, 2006.

3. Chew V, Tow C, Teo M, et al: Inflammatory tumour microenvironment is associated with superior survival in hepatocellular carcinoma patients. J Hepatol 52: 370-379, 2010.

4. Wong CM and Ng IO: Molecular pathogenesis of hepatocellular carcinoma. Liver Int 28: 160-174, 2008.

5. Schmitz J, Owyang A, Oldham E, Song Y, Murphy E, McClanahan TK, Zurawski G, Moshrefi M, Qin J, Li X, et al: IL-33, an interleukin-1-like cytokine that signals via the IL-1 receptor-related protein ST2 and induces T helper type 2-associated cytokines. Immunity 23: 479-490, 2005.
6. Milovanovic M, Volarevic V, Radosavljevic G, Jovanovic I, Pejnovic N, Arsenijevic N and Lukic ML: IL-33/ST2 axis in inflammation and immunopathology. Immunol Res 52: 89-99, 2012.

7. Carriere V, Roussel L, Ortega N, Lacorre DA, Americh L, Aguilar L, Bouche G and Girard JP: IL-33, the IL-1-like cytokine ligand for ST2 receptor, is a chromatin-associated nuclear factor in vivo. Proc Natl Acad Sci USA 104: 282-287, 2007.

8. Chen SF, Nieh S, Jao SW, Wu MZ, Liu CL, Chang YC and Lin YS: The paracrine effect of cancer-associated fibroblast-induced interleukin-33 regulates the invasiveness of head and neck squamous cell carcinoma. J Pathol 231: 180-189, 2013.

9. Jovanovic IP, Pejnovic NN, Radosavljevic GD, Pantic JM, Milovanovic MZ, Arsenijevic NN and Lukic ML: Interleukin-33/ST2 axis promotes breast cancer growth and metastases by facilitating intratumoral accumulation of immunosuppressive and innate lymphoid cells. Int J Cancer 134: 1669-1682, 2014

10. Sun P, Ben Q, Tu S, Dong W, Qi X and Wu Y: Serum interleukin-33 levels in patients with gastric cancer. Dig Dis Sci 56: 3596-3601, 2011.

11. Hu LA, Fu Y, Zhang DN and Zhang J: Serum IL-33 as a diagnostic and prognostic marker in non-small cell lung cancer. Asian Pac J Cancer Prev 14: 2563-2566, 2013.

12. Liu J, Shen JX, Hu JL, Huang WH and Zhang GJ: Significance of interleukin-33 and its related cytokines in patients with breast cancers. Front Immunol 5: 141, 2014.

13. Bonilla WV, Fröhlich A, Senn K, Kallert S, Fernandez M, Johnson S, Kreutzfeldt M, Hegazy AN, Schrick C, Fallon PG, et al: The alarmin interleukin-33 drives protective antiviral CD8 ${ }^{+}$ T cell responses. Science 335: 984-989, 2012.

14. Arshad MI, Rauch M, L'Helgoualc'h A, Julia V, Leite-de-Moraes MC, Lucas-Clerc C, Piquet-Pellorce C and Samson M: NKT cells are required to induce high IL-33 expression in hepatocytes during ConA-induced acute hepatitis. Eur J Immunol 41: 2341-2348, 2011.

15. Wang J, Cai Y, Ji H, Feng J, Ayana DA, Niu J and Jiang Y: Serum IL-33 levels are associated with liver damage in patients with chronic hepatitis B. J Interferon Cytokine Res 32: 248-253, 2012.

16. Marvie P, Lisbonne M, L'Helgoualc'h A, Rauch M, Turlin B, Preisser L, Bourd-Boittin K, Théret N, Gascan H, Piquet-Pellorce C and Samson M: Interleukin-33 overexpression is associated with liver fibrosis in mice and humans. J Cell Mol Med 14: 1726-1739, 2010.

17. Zhang P, Liu XK, Chu Z, Ye JC, Li KL, Zhuang WL, Yang DJ and Jiang YF: Detection of interleukin-33 in serum and carcinoma tissue from patients with hepatocellular carcinoma and its clinical implications. J Int Med Res 40: 1654-1661, 2012.

18. Bergis D, Kassis V, Ranglack A, Koeberle V, Piiper A, Kronenberger B, Zeuzem S, Waidmann O and Radeke HH: High serum levels of the interleukin-33 receptor soluble ST2 as a negative prognostic factor in hepatocellular carcinoma. Transl Oncol 6: 311-318, 2013.

19. Sakai N, Van Sweringen HL, Quillin RC, Schuster R, Blanchard J, Burns JM, Tevar AD, Edwards MJ and Lentsch AB: Interleukin-33 is hepatoprotective during liver ischemia/reperfusion in mice. Hepatology 56: 1468-1478, 2012.

20. Edmondson HA and Steiner PE: Primary carcinoma of the liver: A study of 100 cases among 48,900 necropsies. Cancer 7: 462-503, 1954.

21. Zheng R, Wang J, Wu Q, Wang Z, Ou Y, Ma L, Wang M, Wang J and Yang Y: Expression of ALDH1 and TGF $\beta 2$ in benign and malignant breast tumors and their prognostic implications. Int J Clin Exp Pathol 7: 4173-4183, 2014.

22. He XD, Wang Y, Wu Q, Wang HX, Chen ZD, Zheng RS, Wang ZS, Wang JB and Yang Y: Xuebijing protects rats from sepsis challenged with acinetobacter baumannii by promoting annexin A1 expression and inhibiting proinflammatory cytokines secretion. Evid Based Complement Alternat Med 2013: 804940, 2013.

23. Goncalves CK, Fregnani ER, Leon JE, Silva-Sousa YT and Perez DE: Immunohistochemical expression of p63, epidermal growth factor receptor (EGFR) and notch-1 in radicular cysts, dentigerous cysts and keratocystic odontogenic tumors. Braz Dent J 23: 337-343, 2012.

24. Yang Y, Qin SK, Wu Q, Wang ZS, Zheng RS, Tong XH, Liu H, Tao L and He XD: Connexin-dependent gap junction enhancement is involved in the synergistic effect of sorafenib and all-trans retinoic acid on HCC growth inhibition. Oncol Rep 31: 540-550, 2014 
25. Zhang DY and Friedman SL: Fibrosis-dependent mechanisms of hepatocarcinogenesis. Hepatology 56: 769-775, 2012.

26. Baekkevold ES, Roussigné M, Yamanaka T, Johansen FE, Jahnsen FL, Amalric F, Brandtzaeg P, Erard M, Haraldsen G and Girard JP: Molecular characterization of NF-HEV, a nuclear factor preferentially expressed in human high endothelial venules. Am J Pathol 163: 69-79, 2003.

27. Hayakawa H, Hayakawa M, Kume A and Tominaga S: Soluble ST2 blocks interleukin-33 signaling in allergic airway inflammation. J Biol Chem 282: 26369-26380, 2007.

28. Arend WP, Palmer G and Gabay C: IL-1, IL-18, and IL-33 families of cytokines. Immunol Rev 223: 20-38, 2008.

29. Lüthi AU, Cullen SP, McNeela EA, Duriez PJ, Afonina IS, Sheridan C, Brumatti G, Taylor RC, Kersse K, Vandenabeele $\mathrm{P}$, et al: Suppression of interleukin-33 bioactivity through proteolysis by apoptotic caspases. Immunity 31: $84-98,2009$.
30. Cayrol C and Girard JP: The IL-1-like cytokine IL-33 is inactivated after maturation by caspase-1. Proc Natl Acad Sci USA 106: 9021-9026, 2009.

31. Kunes P, Holubcová Z, Kolácková M and Krejsek J: The counter-regulation of atherogenesis: A role for interleukin-33. Acta Medica (Hradec Kralove) 53: 125-129, 2010.

32. Miller AM: Role of IL-33 in inflammation and disease. J Inflamm (Lond) 8: 22, 2011. 